\title{
An Evolutionary Game Analysis on Public Information Communication between the Government and the Public in China
}

\author{
Hongsen Luo, ${ }^{1,2}$ Ying Gao $\mathbb{D}^{1}{ }^{1}$ and Fulei Shi $\mathbb{D}^{1}$ \\ ${ }^{1}$ School of Management and Engineering, Capital University of Economics and Business, Beijing, China \\ ${ }^{2}$ Institute for Public Safety and Emergency Response, Sichuan Normal University, Chengdu 610101, Sichuan, China \\ Correspondence should be addressed to Ying Gao; gaoying517@cueb.edu.cn and Fulei Shi; davidstoneman@163.com
}

Received 22 June 2020; Revised 5 January 2021; Accepted 15 January 2021; Published 3 February 2021

Academic Editor: Ana Me trovi

Copyright (C) 2021 Hongsen Luo et al. This is an open access article distributed under the Creative Commons Attribution License, which permits unrestricted use, distribution, and reproduction in any medium, provided the original work is properly cited.

Public information is a social resource that connects all aspects of social life, regulates social activities and public behaviors, and plays a very important role in influencing public trust. Based on the perspective of communication, we divide the government into two ways to release public information, that is, mass communication and personalized recommendation. Moreover, the public can choose to acquire or not acquire a strategy. Then, this study conducts an evolutionary game between the government and the public to analyze the influence of public information on the public in China. Our objective is to find how the evolutionary path changes between the two players when strategies are changing. Then, a simulation analysis is presented in six scenarios to illustrate the results. The results show that the two players can converge to different stable statuses under different situations.

\section{Introduction}

Public information plays a very important role in influencing public trust in recent years. However, in 2015, the General Office of the State Council pointed out that there were "not in time, inaccurate, unresponsive, and impractical" problems in the construction of Chinese government websites, and the public even had a certain trust crisis on some public information services provided by the government, such as food safety information disclosure. Therefore, how to improve the accessibility and transmissibility of public information and improve the public's overall satisfaction with public information service is an urgent problem to be solved in China.

In the past few decades, many scholars focused on the studies of the social value of public information [1-4]. For example, Cornand and Heinemann [1] argued that public information should always be provided with maximum precision. James and Lawler [2] concluded that better public information is unambiguously beneficial. However, the public's overall satisfaction with public information services is not high in recent years in China. How to solve this kind of problem? It is actually a decision-making problem, which is a special field of game theory.
There are two ways for the government to release public information. The first way is mass communication which is often discussed in these years [5-9]. For example, as Flanagin [5] proposed, mass communication has traditionally been conceptualized as the one-way transmission of messages from a central organizational source to a large and largely anonymous audience. Hume [6] argued that mass communication is a meaningful way to understand the past. Moreover, the second way is the personalized recommendation which is very popular to be studied by the scholars [10-18]. For example, as Chaney et al. [10] proposed, the goal of recommendation is to suggest a set of unobserved items that she will like; personalized recommendation has become a core component in our online experience. With the fast development of the Internet, Lin et al. [11] argued that personalized news recommendation has become a promising research direction. From the above analyses, we find that this literature has made some contributions to their special field; however, our objective in this paper is to explore how the strategies change between the government and the public. When do the government adopt these two ways to release public information, and what is the best choice? Therefore, it is actually a decision-making problem between 
the government and the public which is a special field of game theory.

In recent years, mounting attention has been paid to the evolutionary game; it has been applied to lots of areas, such as supply chain, environmental pollution, and economics [19-23]. For example, Tian [19] established an evolutionary game to study the industrial pollution problem between the government and enterprises. Friedman [22] introduced the applications of the evolutionary game on economics. In our study, from the former analyses, we can see that how the evolutionary path changes on public information communication problem between the government and the public is actually a field of game theory. Therefore, it is very suitable to use this method to handle this problem in our study.

To the best of our knowledge, how the strategies of the evolutionary path between the government and the public are rarely discussed for public information. Moreover, there is little research on studying the influence of public information on the public in China. Therefore, in this paper, our contributions can be summarized as follows: (1) we present a dynamic strategy analysis on the influence of public information on the public in China based on the perspective of communication in an evolutionary game. (2) A numerical simulation is given to illustrate the results.

The rest of this paper is organized as follows: in Section 2, we describe in detail the evolutionary game model between the government and the public. In Section 3, we explore the stability of the evolutionary game. In Section 4, a numerical simulation is presented to illustrate the results. Finally, in Section 5, the conclusions and the future work of this paper are proposed.

\section{Model}

2.1. Research Assumptions. Before establishing the evolutionary game model, some assumptions are shown as follows:

Assumption 1. Public information plays an important role in modern society. The government is responsible for releasing public information and the public can choose whether or not to acquire public information. Therefore, the agents in this evolutionary game are the government and the public. The government is the first player, marked as $(\mathrm{G})$, and the public is the second player, marked as (P). Moreover, we assume that both of these two agents are bounded rational.

Assumption 2. On the one hand, the government can choose different communication modes to release the public information to the public. They can choose a mass communication strategy or personalized recommendation strategy. Then, we assume that the strategy set of the government is \{mass communication, personalized recommendation\}. On the other hand, the public can adopt whether or not to acquire public information. Then, we assume that the strategy set of the public is \{acquire, not acquire\}.
Assumption 3. We assume that the probability of government with mass communication strategy is $x$, so the probability of the government with personalized recommendation strategy is $1-x \cdot x, 1-x \in[0,1]$. In addition, we assume that the probability of the public with the acquire strategy is $y$, so the probability of the public with the not acquire strategy is $1-y \cdot y, 1-y \in[0,1]$. The basic variables symbol and descriptions are shown in Table 1 and the strategy matrix of two agents is shown in Table 2.

\subsection{Parameters.}

(1) In order to establish the payoff matrix of the evolutionary game model between the government and the public, firstly, the costs of the government are presented as follows:

We assume that the government has $n\left(n \in N^{+}\right)$ pieces of public information in a certain time $t$. Then, we assume that the value of information of piece $i(i=$ $1,2,3, \ldots, n)$ is $V_{i}(i=1,2,3, \ldots, n)$. Moreover, in Section 2.1, we have assumed that the government can adopt two kinds of communication modes to release the public information. When the government chooses the mass communication strategy, it will spend a certain cost, and we assume that the cost is $C_{G}^{1}\left(C_{G}^{1}>0\right)$. When the government adopts the personalized recommendation strategy, we assume that the cost is $C_{G}^{2}\left(C_{G}^{2}>0\right)$. As an emerging mode, the personalized recommendation strategy needs to make statistics of users' browsing records, mine users' preference for public information according to their previous browsing records, and then classify users' hobbies. Based on data mining, recommend public information content, which requires a high cost. Therefore, $C_{G}^{2}>C_{G}^{1}$. Furthermore, we assume that the arrival rate of public information to the public is $k_{1}\left\{k_{1} \in(0,1)\right\}$ when the government chooses the mass communication strategy. Also, we assume that the arrival rate of public information to the public is $k_{2}\left\{k_{2} \in(0,1)\right\}$ when the government chooses the personalized recommendation strategy. Here, we assume that the public could acquire more pieces of public information when the government adopts the personalized recommendation strategy. Thus, $k_{1}<k_{2}$.

(2) Secondly, the costs of the public are shown as follows: If the government adopts the personalized recommendation strategy, it is easier for the public to acquire public information. In this situation, we assume that the cost of the public is $C_{P}^{3}\left\{C_{P}^{3} \in(0,+\infty)\right\}$. In addition, if the government adopts the mass communication strategy, it is harder for the public to acquire information. In this situation, we assume that the cost of the public is $C_{P}^{4}\left\{C_{P}^{4} \in(0,+\infty)\right\}$. Thus, $C_{P}^{3}>C_{P}^{4}$. Moreover, if the public chooses the not acquire strategy, we assume that the cost is 0 . 
TABLE 1: Variables symbol and descriptions.

\begin{tabular}{lcc}
\hline Variables & Descriptions & Value range \\
\hline$x$ & Probability of the government with mass communication strategy & $0 \leq x \leq 1$ \\
$y$ & Probability of the public with the acquire strategy & $0 \leq y \leq 1$ \\
$\mathrm{G}$ & The government & - \\
$\mathrm{P}$ & The public & - \\
\hline
\end{tabular}

TABLE 2: The strategy matrix of two agents.

\begin{tabular}{lcc}
\hline & The public $(\mathrm{P})$ \\
\hline The government $(\mathrm{G})$ & $\begin{array}{c}\text { Mass communication, acquire } \\
\text { Personalized recommendation, acquire }\end{array}$ & Mass communication, not acquire \\
& Personalized recommendation, not acquire \\
\hline
\end{tabular}

(3) Thirdly, the benefits of the government and the public are listed as follows:

Firstly, when the government adopts the mass communication strategy and the public chooses the acquire strategy, we assume that the revenue of the public is $R_{P}^{3}$, $R_{P}^{3}=k_{1} \sum_{i=1}^{n} V_{i}$. On the contrary, when the government adopts the personalized recommendation strategy and the public chooses the acquire strategy, we assume that the revenue of the public is $R_{P}^{4}, R_{P}^{4}=k_{2} \sum_{i=1}^{n} V_{i}$. Moreover, if the public chooses the not acquire strategy, the revenue of the public is 0 . Secondly, if the public acquires the public information, we assume that the government could also get revenues which are regarded as the increases of the social welfare. Then, if the government adopts the mass communication strategy, we assume that the revenue of the government is $R_{G}^{1}, R_{G}^{1}=\alpha R_{P}^{3}=\alpha k_{1} \sum_{i=1}^{n} V_{i}, \alpha(\alpha>1)$ is the conversion rate for the revenue of the public. Moreover, if the government adopts the personalized recommendation strategy, we assume that the revenue of the government is $R_{G}^{2}, R_{G}^{2}=\alpha R_{P}^{4}=\alpha k_{2} \sum_{i=1}^{n} V_{i}$.

Based on the above assumptions, all parameters in this model are presented in Table 3. Moreover, the logical framework of this paper is presented in Figure 1.

\subsection{Payoffs of Two Players.}

(1) When the government adopts the mass communication strategy and the public chooses the acquire strategy, the payoff of the government is presented as follows:

$$
\alpha k_{1} \sum_{i=1}^{n} V_{i}-C_{G}^{1}
$$

The payoff of the public is presented as follows:

$$
k_{1} \sum_{i=1}^{n} V_{i}-C_{P}^{3}
$$

(2) When the government adopts the mass communication strategy and the public chooses the not acquire strategy, then the payoff of the public is 0 . Moreover, the payoff of the government is $-C_{G}^{1}$.
(3) When the government adopts the personalized recommendation strategy and the public chooses the acquire strategy, the payoff of the government is presented as follows:

$$
\alpha k_{2} \sum_{i=1}^{n} V_{i}-C_{G}^{2}
$$

The payoff of the public is presented as follows:

$$
k_{2} \sum_{i=1}^{n} V_{i}-C_{P}^{4}
$$

(4) When the government adopts the mass communication strategy and the public chooses the not acquire strategy, then the payoff of the public is 0 . Moreover, the payoff of the government is $-C_{G}^{2}$.

Based on the above analyses, the payoff matrix of the model is presented in Table 4 .

2.4. The Evolutionary Game Model. In order to study the evolutionary path between the government and the public, the evolutionary game model is established as follows.

Firstly, the expected return $\pi_{G}^{1}$ of the government with mass communication strategy is given by

$$
\pi_{G}^{1}=y\left(\alpha k_{1} \sum_{i=1}^{n} V_{i}-C_{G}^{1}\right)+(1-y)\left(-C_{G}^{1}\right) .
$$

On the contrary, the expected return $\pi_{G}^{2}$ of the government with the personalized recommendation strategy is given by

$$
\pi_{G}^{2}=y\left(\alpha k_{2} \sum_{i=1}^{n} V_{i}-C_{G}^{2}\right)+(1-y)\left(-C_{G}^{2}\right) .
$$

Besides, the expected return $\bar{\pi}_{G}$ of the government is given by

$$
\bar{\pi}_{G}=x \pi_{G}^{1}+(1-x) \pi_{G}^{2} .
$$

Then, combining equations (5)-(7), the replicated dynamic equation $\pi_{G}(x)$ of the government can be obtained as follows: 
TABLE 3: All parameters and their descriptions.

\begin{tabular}{|c|c|c|}
\hline Parameters & Descriptions & Value \\
\hline$C_{G}^{1}$ & The cost of the government with mass communication strategy & $C_{G}^{1} \in(0,+\infty)$ \\
\hline$C_{G}^{2}$ & The cost of the government with personalized recommendation strategy & $C_{G}^{2} \in(0,+\infty)$ \\
\hline$C_{P}^{3}$ & The cost of the acquire strategy when the government adopts the mass communication strategy & $C_{P}^{3} \in(0,+\infty)$ \\
\hline$C_{P}^{4}$ & The cost of the acquire strategy when the government adopts the personalized recommendation strategy & $C_{P}^{4} \in(0,+\infty)$ \\
\hline$k_{1}$ & Arrival rate when the government chooses the mass communication strategy & $k_{1} \in(0,+\infty)$ \\
\hline$k_{2}$ & Arrival rate when the government chooses the personalized recommendation strategy & $k_{2} \in(0,+\infty)$ \\
\hline$\alpha$ & The conversion rate for the revenue of the public & $\alpha \in(0,+\infty)$ \\
\hline$V_{i}$ & The value of information of piece $i$ & $V_{i} \in(0,+\infty)$ \\
\hline$R_{G}^{1}$ & The revenue of the government with mass communication strategy & $R_{G}^{1} \in(0,+\infty)$ \\
\hline$R_{G}^{2}$ & The revenue of the government with personalized recommendation strategy & $R_{G}^{2} \in(0,+\infty)$ \\
\hline$R_{P}^{3}$ & The revenue of the acquire strategy when the government adopts mass communication strategy & $R_{P}^{3} \in(0,+\infty)$ \\
\hline$R_{P}^{4}$ & The revenue of the acquire strategy when the government adopts the personalized recommendation strategy & $R_{P}^{4} \in(0,+\infty)$ \\
\hline
\end{tabular}

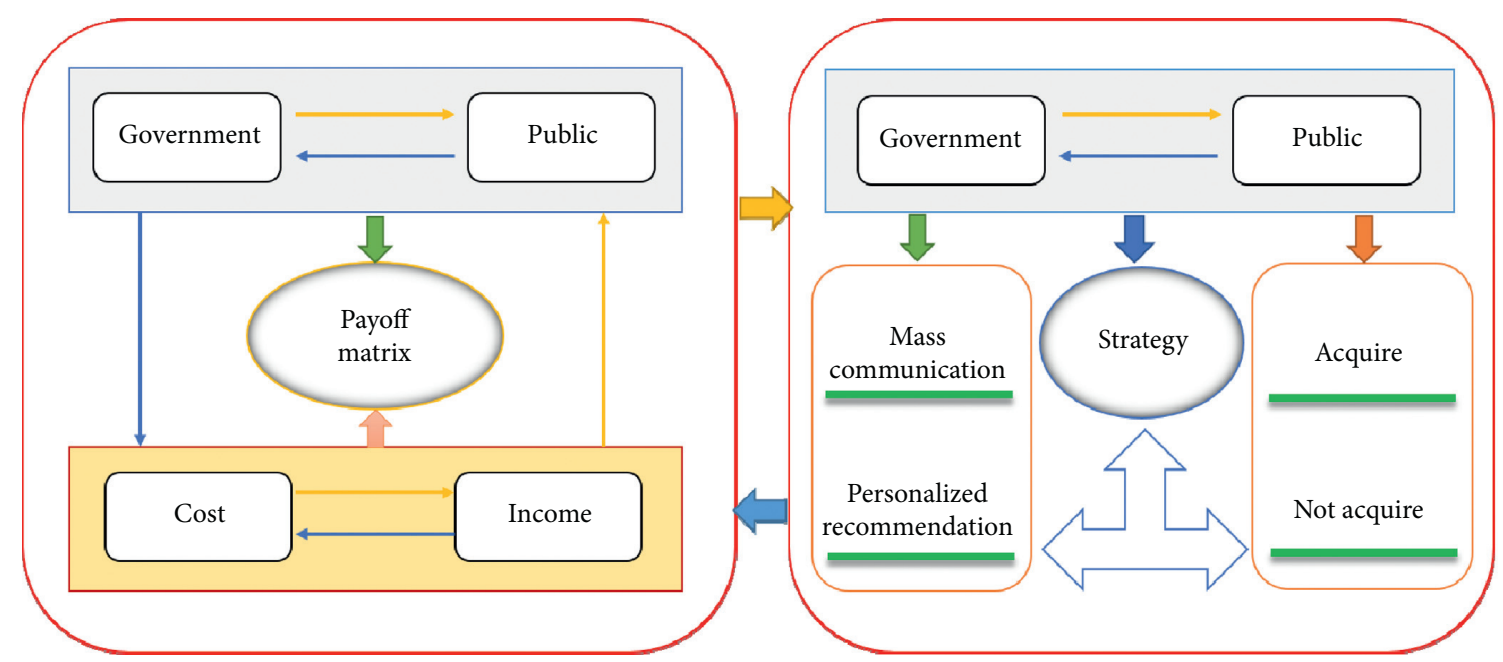

FIgURE 1: The logical framework of this paper.

TABLE 4: The payoff matrix of the model.

\begin{tabular}{|c|c|c|}
\hline & \multicolumn{2}{|c|}{ The public $(\mathrm{G})$} \\
\hline The government $(\mathrm{E})$ & Acquire $(y)$ & Not acquire $(1-y)$ \\
\hline Mass communication $(x)$ & $\left(\alpha k_{1} \sum_{i=1}^{n} V_{i}-C_{G}^{1}, k_{1} \sum_{i=1}^{n} V_{i}-C_{P}^{3}\right)$ & $\left(-C_{G}^{1}, 0\right)$ \\
\hline Personalized recommendation $(1-x)$ & $\left(\alpha k_{2} \sum_{i=1}^{n} V_{i}-C_{G}^{2}, k_{2} \sum_{i=1}^{n} V_{i}-C_{P}^{4}\right)$ & $\left(-C_{G}^{2}, 0\right)$ \\
\hline
\end{tabular}

$$
\pi_{G}(x)=\frac{d x}{d t}=x(1-x)\left[y \alpha\left(k_{1}-k_{2}\right) \sum_{i=1}^{n} V_{i}-\left(C_{G}^{1}-C_{G}^{2}\right)\right] .
$$

Secondly, the expected return $\pi_{P}^{1}$ of the public with the acquire strategy is given by

$$
\pi_{P}^{1}=x\left(k_{1} \sum_{i=1}^{n} V_{i}-C_{P}^{3}\right)+(1-x)\left(k_{2} \sum_{i=1}^{n} V_{i}-C_{P}^{4}\right) .
$$

On the contrary, the expected return $\pi_{P}^{2}$ of the public with the not acquire strategy is given by

$$
\pi_{P}^{2}=x \times 0+(1-x) \times 0=0 .
$$

Besides, the expected return $\bar{\pi}_{P}$ of the public is given by

$$
\bar{\pi}_{P}=y \pi_{P}^{1}+(1-y) \pi_{P}^{2}
$$

Then, combining equations (9)-(11), the replicated dynamic equation $\pi_{P}(y)$ of the public can be obtained as follows:

$$
\begin{aligned}
\pi_{P}(y)= & \frac{d y}{\mathrm{~d} t}=y(1-y)\left\{\left[x k_{1}+(1-x) k_{2}\right] \sum_{i=1}^{n} V_{i}\right. \\
& \left.-x\left(C_{P}^{3}-C_{P}^{4}\right)-C_{P}^{4}\right\} .
\end{aligned}
$$


Thus, according to equations (12) and (21), a dynamic system $S_{1}$ is given by

$$
\left\{\begin{array}{l}
\pi_{G}(x)=\frac{d x}{\mathrm{~d} t}=x(1-x)\left[y \alpha\left(k_{1}-k_{2}\right) \sum_{i=1}^{n} V_{i}-\left(C_{G}^{1}-C_{G}^{2}\right)\right] \\
\pi_{P}(y)=\frac{d y}{\mathrm{~d} t}=y(1-y)\left\{\left[x k_{1}+(1-x) k_{2}\right] \sum_{i=1}^{n} V_{i}-x\left(C_{P}^{3}-C_{P}^{4}\right)-C_{P}^{4}\right\} .
\end{array}\right.
$$

Then, letting $\pi_{G}(x)=0$ and $\pi_{P}(y)=0$, Theorem 1 can be obtained as follows:

Theorem 1. $(0,0),(0,1),(1,0),(1,1)$ must be four Nash equilibrium points of system $S_{1}$. Moreover, if

$$
\left\{\begin{array}{l}
\left|C_{P}^{4}-k_{2} \sum_{i=1}^{n} V_{i}\right|-\left|\left(k_{1}-k_{2}\right) \sum_{i=1}^{n} V_{i}-\left(C_{P}^{3}-C_{P}^{4}\right)\right|<0 \\
\left(C_{P}^{4}-k_{2} \sum_{i=1}^{n} V_{i}\right)\left[\left(k_{1}-k_{2}\right) \sum_{i=1}^{n} V_{i}-\left(C_{P}^{3}-C_{P}^{4}\right)\right]>0 \\
\left|C_{G}^{1}-C_{G}^{2}\right|-\left|\alpha\left(k_{1}-k_{2}\right) \sum_{i=1}^{n} V_{i}\right|<0 \\
\left(C_{G}^{1}-C_{G}^{2}\right)\left[\alpha\left(k_{1}-k_{2}\right) \sum_{i=1}^{n} V_{i}\right]>0
\end{array}\right.
$$

then the point $\left(x^{*}, y^{*}\right)$ with $\left(x^{*}=\left(C_{P}^{4}-k_{2} \sum_{i=1}^{n} V_{i} /\left(k_{1}-\right.\right.\right.$ $\left.\left.\left.k_{2}\right) \sum_{i=1}^{n} V_{i}-\left(C_{P}^{3}-C_{P}^{4}\right)\right), y^{*}=\left(C_{G}^{1}-C_{G}^{2} / \alpha\left(k_{1}-k_{2}\right) \sum_{i=1}^{n} V_{i}\right)\right)$ could be a mixed strategy Nash equilibrium point of system $S_{1}$.

Proof. According to equation (13), let $\pi_{G}(x)=0$ and $\pi_{P}(y)=0$; then, it is obvious that $(0,0),(0,1),(1,0),(1,1)$ must be four Nash equilibrium points of system $S_{1}$. Moreover, letting

$$
\left\{\begin{array}{l}
y \alpha\left(k_{1}-k_{2}\right) \sum_{i=1}^{n} V_{i}-\left(C_{G}^{1}-C_{G}^{2}\right)=0, \\
{\left[x k_{1}+(1-x) k_{2}\right] \sum_{i=1}^{n} V_{i}-x\left(C_{P}^{3}-C_{P}^{4}\right)-C_{P}^{4}=0,}
\end{array}\right.
$$

we can obtain that $\left(x^{*}, y^{*}\right)$ with $\left(x^{*}=\left(C_{P}^{4}-k_{2} \sum_{i=1}^{n}\right.\right.$ $\left.\left.V_{i} /\left(k_{1}-k_{2}\right) \sum_{i=1}^{n} V_{i}-\left(C_{P}^{3}-C_{P}^{4}\right)\right)\right), y^{*}=\left(C_{G}^{1}-C_{G}^{2} / \alpha\left(k_{1}-\right.\right.$ $\left.\left.k_{2}\right) \sum_{i=1}^{n} V_{i}\right)$ ) could be a potential mixed strategy Nash equilibrium point of system $S_{1}$. Furthermore, if

$$
\left\{\begin{array}{l}
\left|C_{P}^{4}-k_{2} \sum_{i=1}^{n} V_{i}\right|-\left|\left(k_{1}-k_{2}\right) \sum_{i=1}^{n} V_{i}-\left(C_{P}^{3}-C_{P}^{4}\right)\right|<0 \\
\left(C_{P}^{4}-k_{2} \sum_{i=1}^{n} V_{i}\right)\left[\left(k_{1}-k_{2}\right) \sum_{i=1}^{n} V_{i}-\left(C_{P}^{3}-C_{P}^{4}\right)\right]>0 \\
\left|C_{G}^{1}-C_{G}^{2}\right|-\left|\alpha\left(k_{1}-k_{2}\right) \sum_{i=1}^{n} V_{i}\right|<0 \\
\left(C_{G}^{1}-C_{G}^{2}\right)\left[\alpha\left(k_{1}-k_{2}\right) \sum_{i=1}^{n} V_{i}\right]>0
\end{array}\right.
$$

then we can obtain that

$$
\left\{\begin{array}{l}
0<\frac{C_{P}^{4}-k_{2} \sum_{i=1}^{n} V_{i}}{\left(k_{1}-k_{2}\right) \sum_{i=1}^{n} V_{i}-\left(C_{P}^{3}-C_{P}^{4}\right)}<1 \\
0<\frac{C_{G}^{1}-C_{G}^{2}}{\alpha\left(k_{1}-k_{2}\right) \sum_{i=1}^{n} V_{i}}<1
\end{array}\right.
$$

Therefore, under this condition, we can obtain that $\left(x^{*}, y^{*}\right)$ is also a mixed strategy Nash equilibrium point of system $S_{1}$.

From Theorem 1, we can obtain that the government and the public will adopt different strategies under different situations. Therefore, we should divide it into different cases to explore the stability of the evolutionary game.

\section{The Stability Analysis of the Evolutionary Game}

3.1. Basic Analysis of the Two Single Players in the Evolutionary Game

Proposition 1. In terms of the public, it will achieve stable status in the following three cases:

(1) When $x=\left(C_{P}^{4}-k_{2} \sum_{i=1}^{n} V_{i} /\left(k_{1}-k_{2}\right) \sum_{i=1}^{n} V_{i}-\left(C_{P}^{3}-\right.\right.$ $\left.C_{P}^{4}\right)$ ), the evolutionary strategy is always in equilibrium 
(2) When $x>\left(C_{P}^{4}-k_{2} \sum_{i=1}^{n} V_{i} /\left(k_{1}-k_{2}\right) \sum_{i=1}^{n} V_{i}-\left(C_{P}^{3}-\right.\right.$ $\left.C_{P}^{4}\right)$ ), then $y=1$ is an evolutionary equilibrium point

(3) When $x<\left(C_{P}^{4}-k_{2} \sum_{i=1}^{n} V_{i} /\left(k_{1}-k_{2}\right) \sum_{i=1}^{n} V_{i}-\left(C_{P}^{3}-\right.\right.$ $\left.\left.C_{P}^{4}\right)\right)$, then $y=0$ is an evolutionary equilibrium point
Proof. According to the work proposed by Friedman [], $\pi_{G}(x)=0$ and $\pi_{G}^{\prime}(x)<0$ are required in order to achieve the "evolutionary stable strategy" (ESS); this is similar for $\pi_{P}(y)$ to meet the same condition. According to equation (13), we can obtain the following equation:

$$
\left\{\begin{array}{l}
\pi_{G}^{\prime}(x)=\frac{d x}{\mathrm{~d} t}=(1-2 x)\left[y \alpha\left(k_{1}-k_{2}\right) \sum_{i=1}^{n} V_{i}-\left(C_{G}^{1}-C_{G}^{2}\right)\right], \\
\pi_{P}^{\prime}(y)=\frac{d y}{\mathrm{~d} t}=(1-2 y)\left\{\left[x k_{1}+(1-x) k_{2}\right] \sum_{i=1}^{n} V_{i}-x\left(C_{P}^{3}-C_{P}^{4}\right)-C_{P}^{4}\right\} .
\end{array}\right.
$$

(1) When $x=\left(C_{P}^{4}-k_{2} \sum_{i=1}^{n} V_{i} /\left(k_{1}-k_{2}\right) \sum_{i=1}^{n} V_{i}-\left(C_{P}^{3}-\right.\right.$ $\left.C_{P}^{4}\right)$ ), there is always $\pi_{P}(y) \equiv 0$. Thus, whatever the value of $y$ is, the evolutionary strategy is always in equilibrium.

(2) When $x>\left(C_{P}^{4}-k_{2} \sum_{i=1}^{n} V_{i} /\left(k_{1}-k_{2}\right) \sum_{i=1}^{n} V_{i}-\left(C_{P}^{3}-\right.\right.$ $\left.\left.C_{p}^{4}\right)\right)$, then there are $\pi_{P}^{\prime}(0)>0$ and $\pi_{P}^{\prime}(1)<0$. Therefore, $y=1$ is an evolutionary equilibrium point, and the public will choose the not acquire strategy.

(3) When $x<\left(C_{P}^{4}-k_{2} \sum_{i=1}^{n} V_{i} /\left(k_{1}-k_{2}\right) \sum_{i=1}^{n} V_{i}-\left(C_{P}^{3}-\right.\right.$ $\left.C_{P}^{4}\right)$ ), then there are $\pi_{P}^{\prime}(0)<0$ and $\pi_{P}^{\prime}(1)>0$. Thus, in this situation, $y=0$ is an evolutionary equilibrium point, and the public will choose the acquire strategy.

Proposition 2. In terms of the government, it will achieve stable status in the following three cases:

(1) When $y=\left(C_{G}^{1}-C_{G}^{2} / \alpha\left(k_{1}-k_{2}\right) \sum_{i=1}^{n} V_{i}\right)$, the evolutionary strategy is always in equilibrium

(2) When $y>\left(C_{G}^{1}-C_{G}^{2} / \alpha\left(k_{1}-k_{2}\right) \sum_{i=1}^{n} V_{i}\right)$, then $x=1$ is an evolutionary equilibrium point

(3) When $y<\left(C_{G}^{1}-C_{G}^{2} / \alpha\left(k_{1}-k_{2}\right) \sum_{i=1}^{n} V_{i}\right)$, then $x=0$ is an evolutionary equilibrium point

Proof. Similar to the proof of Proposition 1, we can obtain the following:

(1) When $y=\left(C_{G}^{1}-C_{G}^{2} / \alpha\left(k_{1}-k_{2}\right) \sum_{i=1}^{n} V_{i}\right)$, there is always $\pi_{G}(x) \equiv 0$. Thus, whatever the value of $x$ is, the evolutionary strategy is always in equilibrium.

(2) When $y>\left(C_{G}^{1}-C_{G}^{2} / \alpha\left(k_{1}-k_{2}\right) \sum_{i=1}^{n} V_{i}\right)$, then there are $\pi_{G}^{\prime}(0)>0$ and $\pi_{G}^{\prime}(1)<0$. Therefore, $x=1$ is an evolutionary equilibrium point, and the government will choose the personalized recommendation strategy.

(3) When $y<\left(C_{G}^{1}-C_{G}^{2} / \alpha\left(k_{1}-k_{2}\right) \sum_{i=1}^{n} V_{i}\right)$, then there are $\pi_{G}^{\prime}(0)<0$ and $\pi_{G}^{\prime}(1)>0$. Thus, in this situation, $x=0$ is an evolutionary equilibrium point, and the government will choose the mass communication strategy.
3.2. Analysis of Stability of the Evolutionary Game. According to the method of the Jacobi matrix proposed by Friedman [18], we assume that the Jacobi matrix of system $S_{1}$ is $J$. Then, the corresponding Jacobi matrix is

$$
J=\left[\begin{array}{ll}
M_{11} & M_{12} \\
M_{21} & M_{22}
\end{array}\right],
$$

where

$$
\begin{aligned}
M_{11}= & \frac{\partial \pi_{G}(x)}{\partial x}=(1-2 x)\left[y \alpha\left(k_{1}-k_{2}\right) \sum_{i=1}^{n} V_{i}-\left(C_{G}^{1}-C_{G}^{2}\right)\right], \\
M_{12}= & \frac{\partial \pi_{G}(x)}{\partial y}=x(1-x)\left(k_{1}-k_{2}\right) \alpha \sum_{i=1}^{n} V_{i}, \\
M_{21}= & \frac{\partial \pi_{P}(y)}{\partial x}=y(1-y)\left[\left(k_{1}-k_{2}\right) \sum_{i=1}^{n} V_{i}-\left(C_{P}^{3}-C_{P}^{4}\right)\right], \\
M_{22}= & \frac{\partial \pi_{P}(y)}{\partial y}=(1-2 y)\left\{\left[x k_{1}+(1-x) k_{2}\right] \sum_{i=1}^{n} V_{i}\right. \\
& \left.-x\left(C_{P}^{3}-C_{P}^{4}\right)-C_{P}^{4}\right\} .
\end{aligned}
$$

Based on the analysis of the Jacobi matrix, we can get the local stability of the equilibrium points; then, Theorem 2 can be obtained as follows.

Theorem 2. The ESS point may be achieved at $(0,0),(0,1)$, $(1,0),(1,1)$; however, $\left(x^{*}, y^{*}\right)$ must be the central point. Moreover, the following six cases are presented:

(1) When $k_{1} \sum_{i=1}^{n} V_{i}-C_{P}^{3}>0, k_{2} \sum_{i=1}^{n} V_{i}-C_{P}^{4}>0$, and $\alpha\left(k_{1}-k_{2}\right) \sum_{i=1}^{n} V_{i}-\left(C_{G}^{1}-C_{G}^{2}\right)>0$, then $(1,1)$ is the ESS point

(2) When $k_{1} \sum_{i=1}^{n} V_{i}-C_{P}^{3}>0, k_{2} \sum_{i=1}^{n} V_{i}-C_{P}^{4}>0$, and $\alpha\left(k_{1}-k_{2}\right) \sum_{i=1}^{n} V_{i}-\left(C_{G}^{1}-C_{G}^{2}\right)<0$, then $(0,1)$ is the ESS point 
(3) When $k_{1} \sum_{i=1}^{n} V_{i}-C_{P}^{3}<0, k_{2} \sum_{i=1}^{n} V_{i}-C_{P}^{4}>0$, and $\alpha\left(k_{1}-k_{2}\right) \sum_{i=1}^{n} V_{i}-\left(C_{G}^{1}-C_{G}^{2}\right)>0$, then $(1,0)$ is the ESS point

(4) When $k_{1} \sum_{i=1}^{n} V_{i}-C_{P}^{3}<0, k_{2} \sum_{i=1}^{n} V_{i}-C_{P}^{4}>0$, and $\alpha\left(k_{1}-k_{2}\right) \sum_{i=1}^{n} V_{i}-\left(C_{G}^{1}-C_{G}^{2}\right)<0$, then the ESS point may be achieved at $(0,1)$ or $(1,0)$

(5) When $k_{1} \sum_{i=1}^{n} V_{i}-C_{P}^{3}<0, k_{2} \sum_{i=1}^{n} V_{i}-C_{P}^{4}>0$, and $\alpha\left(k_{1}-k_{2}\right) \sum_{i=1}^{n} V_{i}-\left(C_{G}^{1}-C_{G}^{2}\right)>0$, then $(1,0)$ is the ESS point
(6) When $k_{1} \sum_{i=1}^{n} V_{i}-C_{P}^{3}<0, k_{2} \sum_{i=1}^{n} V_{i}-C_{P}^{4}<0$, and $\alpha\left(k_{1}-k_{2}\right) \sum_{i=1}^{n} V_{i}-\left(C_{G}^{1}-C_{G}^{2}\right)<0$, then $(1,0)$ is the ESS point

Proof. According to equation (19), we can obtain that the determinant of $J$ as follows:

$$
\begin{aligned}
\operatorname{det} J= & (1-2 x)(1-2 y)\left[y \alpha\left(k_{1}-k_{2}\right) \sum_{i=1}^{n} V_{i}-\left(C_{G}^{1}-C_{G}^{2}\right)\right]\left\{\left[x k_{1}+(1-x) k_{2}\right] \sum_{i=1}^{n} V_{i}-x\left(C_{P}^{3}-C_{P}^{4}\right)\right\} \\
& -x y(1-x)(1-y)\left[\alpha\left(k_{1}-k_{2}\right) \sum_{i=1}^{n} V_{i}\right]\left[\left(k_{1}-k_{2}\right) \sum_{i=1}^{n} V_{i}-\left(C_{P}^{3}-C_{P}^{4}\right)\right] .
\end{aligned}
$$

The trace of the matrix $J$ is

$$
\begin{aligned}
\operatorname{tr} J= & (1-2 x)\left[y \alpha\left(k_{1}-k_{2}\right) \sum_{i=1}^{n} V_{i}-\left(C_{G}^{1}-C_{G}^{2}\right)\right] \\
& +(1-2 y)\left\{\left[x k_{1}+(1-x) k_{2}\right] \sum_{i=1}^{n} V_{i}-x\left(C_{P}^{3}-C_{P}^{4}\right)\right\} .
\end{aligned}
$$

Then, from equations (21) and (22) and the point $\left(x^{*}, y^{*}\right)$, we can obtain

$$
\left\{\begin{array}{l}
\psi_{1}:\left.\operatorname{det} J\right|_{\left(x^{*}, y^{*}\right)}=\left(1-2 x^{*}\right)\left(1-2 y^{*}\right)\left[y^{*} \alpha\left(k_{1}-k_{2}\right) \sum_{i=1}^{n} V_{i}-\left(C_{G}^{1}-C_{G}^{2}\right)\right] \\
\left\{\left[x^{*} k_{1}+\left(1-x^{*}\right) k_{2}\right] \sum_{i=1}^{n} V_{i}-x^{*}\left(C_{P}^{3}-C_{P}^{4}\right)\right\} \\
-x^{*} y^{*}\left(1-x^{*}\right)\left(1-y^{*}\right)\left[\alpha\left(k_{1}-k_{2}\right) \sum_{i=1}^{n} V_{i}\right]\left[\left(k_{1}-k_{2}\right) \sum_{i=1}^{n} V_{i}-\left(C_{P}^{3}-C_{P}^{4}\right)\right] \\
=\frac{\left(k_{1} \sum_{i=1}^{n} V_{i}-C_{P}^{3}\right)\left(k_{2} \sum_{i=1}^{n} V_{i}-C_{P}^{4}\right)\left(C_{G}^{1}-C_{G}^{2}\right)\left[\alpha\left(k_{1}-k_{2}\right) \sum_{i=1}^{n} V_{i}-\left(C_{G}^{1}-C_{G}^{2}\right)\right]}{\left[\alpha\left(k_{1}-k_{2}\right) \sum_{i=1}^{n} V_{i}\right]\left[\left(k_{1}-k_{2}\right) \sum_{i=1}^{n} V_{i}-\left(C_{P}^{3}-C_{P}^{4}\right)\right]} \\
\psi_{2}:\left.\operatorname{tr} J\right|_{\left(x^{*}, y^{*}\right)}=\left(1-2 x^{*}\right)\left[y^{*} \alpha\left(k_{1}-k_{2}\right) \sum_{i=1}^{n} V_{i}-\left(C_{G}^{1}-C_{G}^{2}\right)\right]+\left(1-2 y^{*}\right) \\
\left\{\begin{array}{l}
\left.\left[x^{*} k_{1}+\left(1-x^{*}\right) k_{2}\right] \sum_{i=1}^{n} V_{i}-x^{*}\left(C_{P}^{3}-C_{P}^{4}\right)\right\}=0 .
\end{array}\right.
\end{array}\right.
$$

According to equation (23), we know that $\left.\operatorname{tr} J\right|_{\left(x^{*}, y^{*}\right)}=0$; therefore, the trace of the matrix under different situations must be 0 . Thus, $\left(x^{*}, y^{*}\right)$ must be the central point. Moreover, we can obtain that the expressions of five points as shown in Table 5.
Moreover, according to the work proposed by Friedman [], the corresponding evolutionary strategy will become the ESS point if $\operatorname{det} J>0$ and $\operatorname{tr} J<0$. In Section 2.2, we assume that the parameters in this model are all positive; in addition, $C_{G}^{2}>C_{G}^{1}, C_{P}^{3}>C_{P}^{4}$, and $k_{1}<k_{2}$. Thus, there must be 
TABLE 5: The expressions of five points.

\begin{tabular}{lcc}
\hline $\begin{array}{l}\text { Equilibrium } \\
\text { point }\end{array}$ & Expression \\
\hline & $\operatorname{det} J$ & $-\left(C_{G}^{1}-C_{G}^{2}\right)\left(k_{2} \sum_{i=1}^{n} V_{i}-C_{P}^{4}\right)$ \\
& $\operatorname{tr} J$ & $-\left(C_{G}^{1}-C_{G}^{2}\right)+\left(k_{2} \sum_{i=1}^{n} V_{i}-C_{P}^{4}\right)$ \\
& $\operatorname{det} J$ & $-\left[\alpha\left(k_{1}-k_{2}\right) \sum_{i=1}^{n} V_{i}-\left(C_{G}^{1}-C_{G}^{2}\right)\right]\left(k_{2} \sum_{i=1}^{n} V_{i}-C_{P}^{4}\right)$ \\
$(0,1)$ & $\operatorname{tr} J$ & $\left(\alpha\left(k_{1}-k_{2}\right) \sum_{i=1}^{n} V_{i}-\left(C_{G}^{1}-C_{G}^{2}\right)\right]-\left(k_{2} \sum_{i=1}^{n} V_{i}-C_{P}^{4}\right)$ \\
& $\operatorname{det} J$ & $\left(C_{G}^{1}-C_{G}^{2}\right)\left(k_{1} \sum_{i=1}^{n} V_{i}-C_{P}^{3}\right)$ \\
$(1,0)$ & $\operatorname{tr} J$ & $\left(C_{G}^{1}-C_{G}^{2}\right)+\left(k_{1} \sum_{i=1}^{n} V_{i}-C_{P}^{3}\right)$ \\
& $\operatorname{det} J$ & $-\left[\alpha\left(k_{1}-k_{2}\right) \sum_{i=1}^{n} V_{i}-\left(C_{G}^{1}-C_{G}^{2}\right)\right]-\left(k_{1} \sum_{i=1}^{n} V_{i}-C_{P}^{3}\right)$ \\
$(1,1)$ & $\operatorname{tr} J$ & $\left.\left(C_{P}^{3}-C_{P}^{4}\right)\right]$ \\
& & 0 \\
$\left(x^{*}, y^{*}\right)$ & $\operatorname{det} J$ & $\left(k_{1} \sum_{i=1}^{n} V_{i}-C_{P}^{3}\right)\left(k_{2} \sum_{i=1}^{n} V_{i}-C_{P}^{4}\right)\left(C_{G}^{1}-C_{G}^{2}\right)\left[\alpha\left(k_{1}-k_{2}\right) \sum_{i=1}^{n} V_{i}-\left(C_{G}^{1}-C_{G}^{2}\right)\right] /\left[\alpha\left(k_{1}-k_{2}\right) \sum_{i=1}^{n} V_{i}\right]\left[\left(k_{1}-k_{2}\right) \sum_{i=1}^{n} V_{i}-\right.$ \\
& $\operatorname{tr} J$ &
\end{tabular}

$C_{G}^{1}-C_{G}^{2}<0, C_{P}^{3}-C_{P}^{4}>0$, and $k_{1}-k_{2}<0$. Then, we can obtain that $\alpha\left(k_{1}-k_{2}\right) \sum_{i=1}^{n} V_{i}<0$ and $\left(k_{1}-k_{2}\right) \sum_{i=1}^{n} V_{i}-$ $\left(C_{P}^{3}-C_{P}^{4}\right)<0$. Therefore, we just need to discuss the following three cases:

When $k_{1} \sum_{i=1}^{n} V_{i}-C_{P}^{3}>0$, due to $C_{P}^{3}>C_{P}^{4}$ and $k_{1}<k_{2}$, there must be $k_{2} \sum_{i=1}^{n} V_{i}-C_{P}^{4}>0$. Therefore, the following two cases are discussed:

(1) When $k_{1} \sum_{i=1}^{n} V_{i}-C_{P}^{3}>0, k_{2} \sum_{i=1}^{n} V_{i}-C_{P}^{4}>0$, and $\alpha\left(k_{1}-k_{2}\right) \sum_{i=1}^{n} V_{i}-\left(C_{G}^{1}-C_{G}^{2}\right)>0$, then we have $\left.\operatorname{det} J\right|_{(1,1)}=\left[\alpha\left(k_{1}-k_{2}\right) \sum_{i=1}^{n} V_{i}-\left(C_{G}^{1}-C_{G}^{2}\right)\right]\left(k_{1} \sum_{i=1}^{n}\right.$ $\left.V_{i}-C_{P}^{3}\right)>0$ and $\left.\operatorname{tr} J\right|_{(1,1)}=-\left[\alpha\left(k_{1}-k_{2}\right) \sum_{i=1}^{n} V_{i}-\right.$ $\left.\left(C_{G}^{1}-C_{G}^{2}\right)\right]-\left(k_{1} \sum_{i=1}^{n} V_{i}-C_{P}^{3}\right)<0$. Therefore, $(1,1)$ is the ESS point.

(2) When $k_{1} \sum_{i=1}^{n} V_{i}-C_{P}^{3}>0, k_{2} \sum_{i=1}^{n} V_{i}-C_{P}^{4}>0$, and $\alpha\left(k_{1}-k_{2}\right) \sum_{i=1}^{n} V_{i}-\left(C_{G}^{1}-C_{G}^{2}\right)<0$, then we have $\left.\operatorname{det} J\right|_{(0,1)}=-\left[\alpha\left(k_{1}-k_{2}\right) \sum_{i=1}^{n} V_{i}-\left(C_{G}^{1}-C_{G}^{2}\right)\right]\left(k_{2} \sum_{i=1}^{n}\right.$ $\left.V_{i}-C_{P}^{4}\right)>0$ and $\left.\operatorname{tr} J\right|_{(0,1)}=\left[\alpha\left(k_{1}-k_{2}\right) \sum_{i=1}^{n} V_{i}-\right.$ $\left.\left(C_{G}^{1}-C_{G}^{2}\right)\right]-\left(k_{2} \sum_{i=1}^{n} V_{i}-C_{P}^{4}\right)<0$. Therefore, $(0,1)$ is the ESS point.

When $k_{1} \sum_{i=1}^{n} V_{i}-C_{P}^{3}<0$, the following four cases are shown in Table 6 .

\section{Simulation Analysis}

4.1. The Evolutionary Path between the Government and the Public. In order to observe the evolutionary path between the government and the public, simulation analyses are used. Then, according to Theorem 2, the assumed values of the parameters under the six scenarios are presented in Table 7.

To simplify the analysis, we assume that $\alpha=2, n=3$, and $V_{i}=5$ in six scenarios. Moreover, in order to fully discuss the influence of different initial values of probabilities to the stability of the model, we assume that $x=y=\left(\begin{array}{ll}0.1: 0.2: 0.9\end{array}\right)$. For example, if $x=0.1, y=0.1$, it means that the government will adopt a weak willingness to choose the mass communication strategy while the enterprises will also adopt a weak willingness to choose the acquire strategy. If $x=0.1, y=0.9$, it means that the government will adopt a weak willingness to choose the mass communication strategy while the enterprises will also adopt a high willingness to choose the acquire strategy. Then, the simulation results of six scenarios are presented in Figure 2.

From Figure 2 and combined with Theorem 2, we can obtain the following conclusions.

Conclusion 1. Combined with Figures 2(a) and 2(b) and Theorem 2, we can see that when $k_{1} \sum_{i=1}^{n} V_{i}-C_{P}^{3}>0$, $k_{2} \sum_{i=1}^{n} V_{i}-C_{P}^{4}>0$, and $\alpha\left(k_{1}-k_{2}\right) \sum_{i=1}^{n} V_{i}-\left(C_{G}^{1}-C_{G}^{2}\right)>0$, then $(1,1)$ is the ESS point. Therefore, in this situation, the government will fully adopt the mass communication strategy and the public will fully adopt the acquire strategy. When $k_{1} \sum_{i=1}^{n} V_{i}-C_{P}^{3}>0, \quad k_{2} \sum_{i=1}^{n} V_{i}-C_{P}^{4}>0$, and $\alpha\left(k_{1}-k_{2}\right) \sum_{i=1}^{n} V_{i}-\left(C_{G}^{1}-C_{G}^{2}\right)<0$, then $(0,1)$ is the ESS point. In this situation, the government will adopt the personalized recommendation strategy while the public adopts the acquire strategy. These two scenarios are very similar because the public will choose the acquire strategy. This is mainly due to the condition that $k_{1} \sum_{i=1}^{n} V_{i}-C_{P}^{3}>0$; thus, the revenue of the public with the acquire strategy is higher than the cost.

Conclusion 2. Combined with Figures 2(c) and 2(f) and Theorem 2, we can see that when $k_{1} \sum_{i=1}^{n} V_{i}-C_{P}^{3}<0$, $k_{2} \sum_{i=1}^{n} V_{i}-C_{P}^{4}>0$, and $\alpha\left(k_{1}-k_{2}\right) \sum_{i=1}^{n} V_{i}-\left(C_{G}^{1}-C_{G}^{2}\right)>0$; when $k_{1} \sum_{i=1}^{n} V_{i}-C_{P}^{3}<0, k_{2} \sum_{i=1}^{n} V_{i}-C_{P}^{4}<0$, and $\alpha\left(k_{1}-k_{2}\right)$ $\sum_{i=1}^{n} V_{i}-\left(C_{G}^{1}-C_{G}^{2}\right)>0$; or when $k_{1} \sum_{i=1}^{n} V_{i}-C_{P}^{3}<0$, $k_{2} \sum_{i=1}^{n} V_{i}-C_{P}^{4}<0$, and $\alpha\left(k_{1}-k_{2}\right) \sum_{i=1}^{n} V_{i}-\left(C_{G}^{1}-C_{G}^{2}\right)<0$, the ESS point is always $(0,0)$. That is to say, in these three situations, the government will choose the personalized recommendation strategy and the public will choose the not acquire strategy. Moreover, when $k_{1} \sum_{i=1}^{n} V_{i}-C_{P}^{3}<0$, $k_{2} \sum_{i=1}^{n} V_{i}-C_{P}^{4}>0$, and $\alpha\left(k_{1}-k_{2}\right) \sum_{i=1}^{n} V_{i}-\left(C_{G}^{1}-C_{G}^{2}\right)<0$, then three are two ESS points, $(0,1)$ and $(1,0)$. In this case, the strategies can be different between the government and the public. 
TABLE 6: The evolutionary stability of local equilibrium points under four cases.

\begin{tabular}{|c|c|c|c|c|c|}
\hline Case & Condition & Equilibrium point & $\operatorname{det} J$ & $\operatorname{tr} J$ & Results \\
\hline \multirow[t]{2}{*}{ Case 1} & $k_{1} \sum_{i=1}^{n} V_{i}-C_{P}^{3}<0$ & $(0,0)$ & + & + & Unstable point \\
\hline & $k_{2} \sum_{i=1}^{n} V_{i}-C_{P}^{4}>0$ & $(0,1)$ & - & \pm & Saddle point \\
\hline \multirow{3}{*}{ (3) } & $\alpha\left(k_{1}-k_{2}\right) \sum_{i=1}^{n} V_{i}-\left(C_{G}^{1}-C_{G}^{2}\right)>0$ & $(1,0)$ & + & - & ESS \\
\hline & & $(1,1)$ & - & \pm & Saddle point \\
\hline & & $\left(x^{*}, y^{*}\right)$ & + & $\overline{0}$ & Central point \\
\hline \multirow[t]{2}{*}{ Case 2} & $k_{1} \sum_{i=1}^{n} V_{i}-C_{P}^{3}<0$ & $(0,0)$ & + & + & Unstable point \\
\hline & $k_{2} \sum_{i=1}^{n} V_{i}-C_{P}^{4}>0$ & $(0,1)$ & + & - & ESS \\
\hline \multirow{3}{*}{ (4) } & $\alpha\left(k_{1}-k_{2}\right) \sum_{i=1}^{n=1} V_{i}-\left(C_{G}^{1}-C_{G}^{2}\right)<0$ & $(1,0)$ & + & - & ESS \\
\hline & & $(1,1)$ & + & + & Unstable point \\
\hline & & $\left(x^{*}, y^{*}\right)$ & - & 0 & Central point \\
\hline \multirow[t]{2}{*}{ Case 3} & $k_{1} \sum_{i=1}^{n} V_{i}-C_{P}^{3}<0$ & $(0,0)$ & - & \pm & Saddle point \\
\hline & $k_{2} \sum_{i=1}^{n} V_{i}-C_{P}^{4}<0$ & $(0,1)$ & - & \pm & Saddle point \\
\hline \multirow{3}{*}{ (5) } & $\alpha\left(k_{1}-k_{2}\right) \sum_{i=1}^{n-1} V_{i}-\left(C_{G}^{1}-C_{G}^{2}\right)>0$ & $(1,0)$ & + & - & ESS \\
\hline & & $(1,1)$ & - & \pm & Saddle point \\
\hline & & $\left(x^{*}, y^{*}\right)$ & - & 0 & Central point \\
\hline \multirow[t]{2}{*}{ Case 4} & $k_{1} \sum_{i=1}^{n} V_{i}-C_{P}^{3}<0$ & $(0,0)$ & - & \pm & Saddle point \\
\hline & $k_{2} \sum_{i=1}^{n} V_{i}-C_{P}^{4}<0$ & $(0,1)$ & - & \pm & Saddle point \\
\hline \multirow{3}{*}{ (6) } & $\alpha\left(k_{1}-k_{2}\right) \sum_{i=1}^{n} V_{i}-\left(C_{G}^{1}-C_{G}^{2}\right)<0$ & $(1,0)$ & + & - & ESS \\
\hline & & $(1,1)$ & + & + & Unstable point \\
\hline & & $\left(x^{*}, y^{*}\right)$ & + & 0 & Central point \\
\hline
\end{tabular}

From Table 6, we can obtain the cases in (3) (6).

TABLE 7: The assumed values of the parameters under the six scenarios.

\begin{tabular}{|c|c|c|c|c|c|c|}
\hline The scenarios & Scenario (1) & Scenario (2) & Scenario (3) & Scenario (4) & Scenario (5) & Scenario (6) \\
\hline$k_{1}$ & 0.3 & 0.3 & 0.3 & 0.3 & 0.3 & 0.3 \\
\hline$k_{2}$ & 0.7 & 0.7 & 0.7 & 0.7 & 0.7 & 0.7 \\
\hline$n$ & 3 & 3 & 3 & 3 & 3 & 3 \\
\hline$V_{i}$ & 5 & 5 & 5 & 5 & 5 & 5 \\
\hline$C_{P}^{3}$ & 3 & 3 & 5 & 5 & 15 & 15 \\
\hline$C_{P}^{4}$ & 2 & 2 & 2 & 2 & 12 & 12 \\
\hline$C_{G}^{1}$ & 2 & 2 & 2 & 2 & 2 & 2 \\
\hline$C_{G}^{2}$ & 15 & 10 & 15 & 10 & 15 & 10 \\
\hline$\alpha$ & 2 & 2 & 2 & 2 & 2 & 2 \\
\hline$x$ & $(0.1: 0.2: 0.9)$ & $(0.1: 0.2: 0.9)$ & $(0.1: 0.2: 0.9)$ & $(0.1: 0.2: 0.9)$ & $(0.1: 0.2: 0.9)$ & $(0.1: 0.2: 0.9)$ \\
\hline$y$ & $(0.1: 0.2: 0.9)$ & $(0.1: 0.2: 0.9)$ & $(0.1: 0.2: 0.9)$ & $(0.1: 0.2: 0.9)$ & $(0.1: 0.2: 0.9)$ & $(0.1: 0.2: 0.9)$ \\
\hline
\end{tabular}

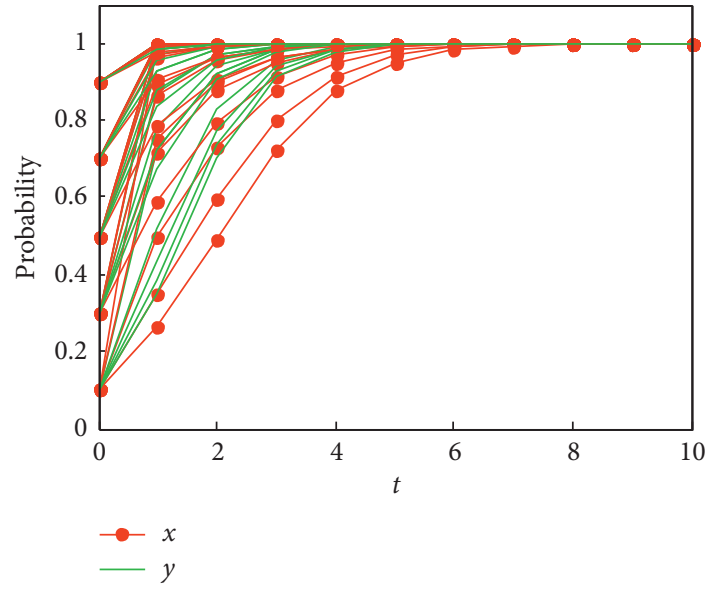

(a)

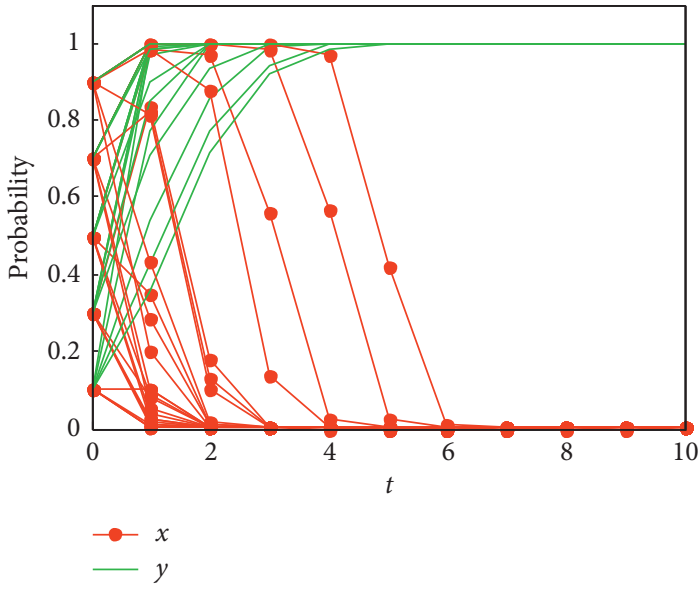

(b)

Figure 2: Continued. 


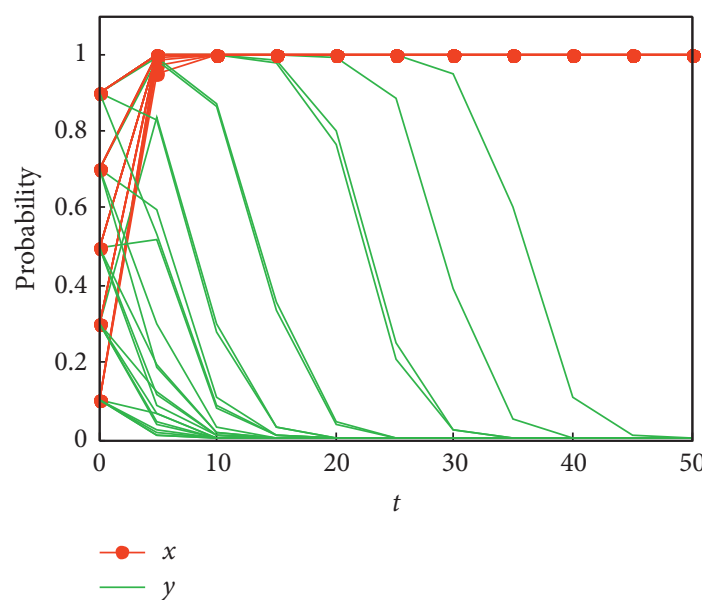

(c)

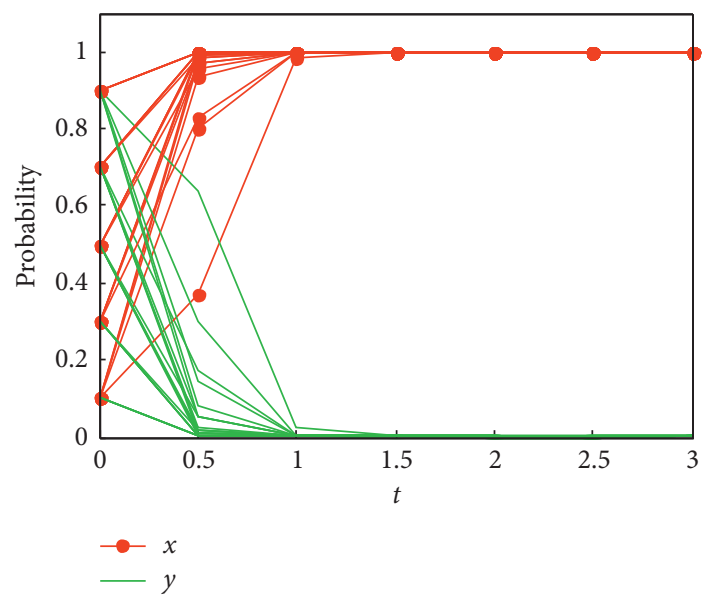

(e)

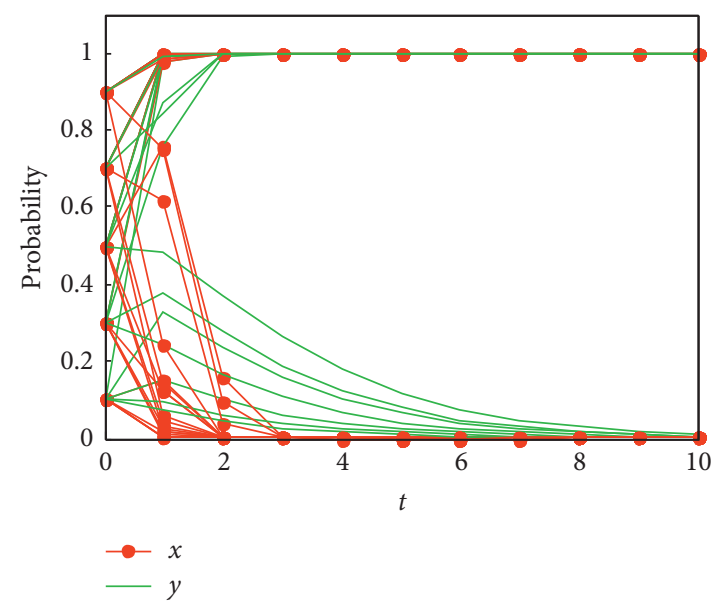

(d)

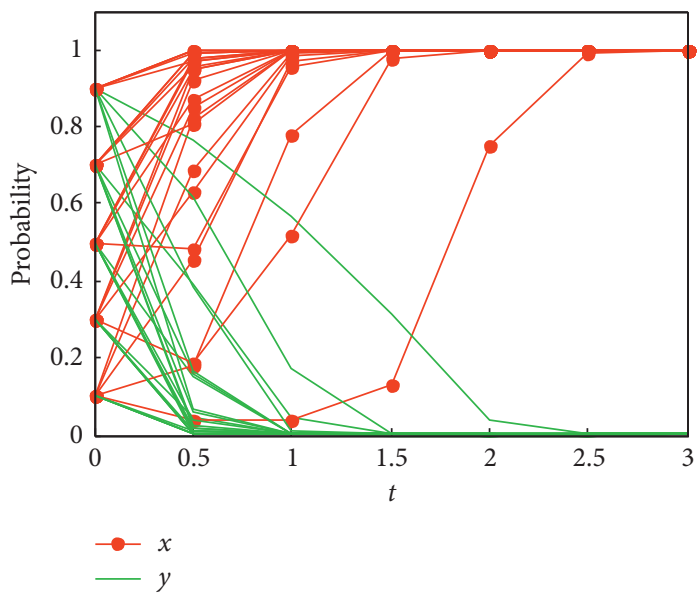

(f)

FIgURE 2: The simulation results of six scenarios.

Conclusion 3. Combined with the above six scenarios, we can obtain that the time to convergence is different; in Scenario (3), it will spend more time to converge to a stable status.

\section{Conclusions and Policy Recommendations}

This paper conducts an evolutionary game on public information communication between the government and the public. Then, the stability of the evolutionary under different cases is explored. Moreover, the simulation analysis is presented to illustrate the results. The results can be affected by differential situations. The strategies selected by the government and the public are mainly influenced by their cost and revenue. Reducing the cost of different communication strategies of the government will help to improve the arrival rate of public information and improve the efficiency of public access. Furthermore, the evolutionary path under different scenarios can converge to different stable statuses.
With the rapid development of the Internet, the dissemination of public information has become more convenient. It requires the joint efforts of all parties in the system to improve the public's overall satisfaction with public information services, makes targeted personalized recommendations on public information, and improves the effectiveness and arrival rate of communication. Based on the above analyses results, several policies suggestions are proposed as follows: reducing the cost of the "personalized recommendation" of public information and mining the information required by users can avoid resource waste, improve the efficiency of public access, and thus enhance the overall satisfaction of the public on public information dissemination. Moreover, on the one hand, we can establish a good user information feedback mechanism which is called "the user access, personalized recommendation, and customer satisfaction." On the other hand, the dissemination of public information should be regulated reasonably, and the release of public information should be subject to a strict review mechanism, so as to reduce or even eliminate the release of 
inferior public information, to improve the dissemination quality of public information and meet the public demand for public information in a real sense.

\section{Limitations and Future Work}

There are also some limitations to our study due to the fact that the data we used in our paper is the simulated data. Therefore, in future work, we can use real cases to explore the evolutionary path on public information communication between the government and the public.

\section{Data Availability}

The simulation data used to support the findings of this study are included within the article.

\section{Conflicts of Interest}

The authors declare that they have no conflicts of interest.

\section{Acknowledgments}

This work was supported by the Beijing Social Science Foundation Project, China (Grant no. 16SRB021) and the projects of Education Department of Sichuan Province (no. 18ZA0406), Chengdu Philosophy and Social Science Planning Research Project (no. YN2320200699), and Sichuan Normal University 2020 Global Governance and Regional Country Studies Special International Cooperation Project (no. GJYB2020002).

\section{References}

[1] C. Cornand and F. Heinemann, "Optimal degree of public information dissemination," The Economic Journal, vol. 118, no. 528, pp. 718-742, 2008.

[2] J. G. James and P. Lawler, "Optimal policy intervention and the social value of public information," American Economic Review, vol. 101, no. 4, pp. 1561-1574, 2011.

[3] S. Morris and H. S. Shin, "Social value of public information," American Economic Review, vol. 92, no. 5, pp. 1521-1534, 2002.

[4] J. Hirshleifer, "The private and social value of information and the reward to inventive activity," in Uncertainty in Economics, pp. 541-556, Academic Press, Cambridge, MA, USA, 1978.

[5] A. J. Flanagin, "Online social influence and the convergence of mass and interpersonal communication," Human Communication Research, vol. 43, no. 4, pp. 450-463, 2017.

[6] J. Hume, "Memory matters: the evolution of scholarship in collective memory and mass communication," Review of Communication, vol. 10, no. 3, pp. 181-196, 2010.

[7] L. Guo, C. J. Vargo, Z. Pan, W. Ding, and P. Ishwar, "Big social data analytics in journalism and mass communication," Journalism \& Mass Communication Quarterly, vol. 93, no. 2, pp. 332-359, 2016.

[8] R. M. Perloff, "Mass communication research at the crossroads: definitional issues and theoretical directions for mass and political communication scholarship in an age of online media," Mass Communication and Society, vol. 18, no. 5, pp. 531-556, 2015.
[9] E. Thorson, R. Wicks, and G. Leshner, "Experimental methodology in journalism and mass communication research," Journalism \& Mass Communication Quarterly, vol. 89, no. 1, pp. 112-124, 2012.

[10] A. J. B. Chaney, D. M. Blei, and T. Eliassi-Rad, "A probabilistic model for using social networks in personalized item recommendation," in Proceedings of the 9th ACM Conference on Recommender Systems, pp. 43-50, ACM, New York, NY, USA, 2015.

[11] C. Lin, R. Xie, X. Guan, L. Li, and T. Li, "Personalized news recommendation via implicit social experts," Information Sciences, vol. 254, pp. 1-18, 2014.

[12] F. Abel, Q. Gao, G. J. Houben et al., "Analyzing user modeling on twitter for personalized news recommendations," in Proceedings of the International Conference on User Modeling, Adaptation, and Personalization, pp. 1-12, Springer, Girona, Spain, July 2011.

[13] X. Amatriain, "Mining large streams of user data for personalized recommendations," ACM SIGKDD Explorations Newsletter, vol. 14, no. 2, pp. 37-48, 2013.

[14] D. Geiger and M. Schader, "Personalized task recommendation in crowdsourcing information systems-current state of the art," Decision Support Systems, vol. 65, pp. 3-16, 2014.

[15] C.-K. Hsu, G.-J. Hwang, and C.-K. Chang, "A personalized recommendation-based mobile learning approach to improving the reading performance of EFL students," Computers \& Education, vol. 63, pp. 327-336, 2013.

[16] S. Jiang, X. Qian, T. Mei, and Y. Fu, "Personalized travel sequence recommendation on multi-source big social media," IEEE Transactions on Big Data, vol. 2, no. 1, pp. 43-56, 2016.

[17] L. Li, L. Zheng, F. Yang, and T. Li, "Modeling and broadening temporal user interest in personalized news recommendation," Expert Systems with Applications, vol. 41, no. 7, pp. 3168-3177, 2014.

[18] A. Majid, L. Chen, G. Chen, H. T. Mirza, I. Hussain, and J. Woodward, "A context-aware personalized travel recommendation system based on geotagged social media data mining," International Journal of Geographical Information Science, vol. 27, no. 4, pp. 662-684, 2013.

[19] Y. Tian, K. Govindan, and Q. Zhu, "A system dynamics model based on evolutionary game theory for green supply chain management diffusion among Chinese manufacturers," Journal of Cleaner Production, vol. 80, pp. 96-105, 2014.

[20] C. Wang and F. Shi, "An evolutionary game model for industrial pollution management under two punishment mechanisms," International Journal of Environmental Research and Public Health, vol. 16, no. 15, p. 2775, 2019.

[21] D. Friedman, "Evolutionary games in economics," Econometrica, vol. 59, no. 3, pp. 637-666, 1991.

[22] D. Friedman, "On economic applications of evolutionary game theory," Journal of Evolutionary Economics, vol. 8, no. 1, pp. 15-43, 1998.

[23] D. Friedman, "Evolutionary economics goes mainstream: a review of the theory of learning in games," Journal of Evolutionary Economics, vol. 8, no. 4, pp. 423-432, 1998. 